\title{
Sustaining an Equitable Heath System: Need for Evidence Informed Decision Making
}

Weerasinghe MC* $^{*}$

Department of Community Medicine, University of Colombo, Sri Lanka

${ }^{*}$ Corresponding author: Manuj Chrishantha Weerasinghe, Department of Community Medicine, University of Colombo, Sri Lanka, Tel: +94112695300; E-mail: manujchri@gmail.com

Received date: January 12, 2016; Accepted date: July 27, 2017; Published date: August 3, 2017

Copyright: ( 2017 Weerasinghe MC. This is an open-access article distributed under the terms of the Creative Commons Attribution License, which permits unrestricted use, distribution, and reproduction in any medium, provided the original author and source are credited.

\section{Abstract}

Provision of universal health coverage has drawn attention across the globe. Attaining equity in service provision while sustaining the health system has become the major challenge. As limited resources become a barrier to achieve both at the same time, short term measures dominate policy cycles based on options and interests of individuals and groups than hard evidence. Taking Sri Lankan health system as an example this paper discusses the importance of evidence based decisions to achieve both equity and sustainability of services in low resource settings.

Keywords: Heath systems; Disease; Human resources; Healthcare

\section{Introduction}

In every human society, diseases have generated some form of response aimed at interpreting, controlling, preventing, alleviating repairing, curing or healing injury, illness and disease. All these forms of deliberate response to disease regardless of their nature comprise a health system [1]. The term heath systems sometimes also referred to as 'medical systems' is for the organized array of human resources, technologies and services specifically designed for the development and practice of medicine for an individual or collective health care. In a strict sense, medical systems are made up of a more or less uniform set of schools, hospitals, clinics, professional associations and agencies that train personal, maintain an infrastructure for biomedical research and deploy a network of services of varying degree of complexity for the prevention, cure, care and rehabilitation of the sick.

A functional health system as put forward by the World Health Organization comprises of six elements that should work hand in hand to deliver desired outcomes [2]. The elements include leadership and governance, health information system, health financing, human resources for health, essential medical products and technologies and service delivery. In order to sustain those five elements in a functional manner and to deliver equitable solutions to the population, it is mandatory that decisions are made in an informed manner rather than arbitrarily. Maintaining and strengthening equitable health systems that are also sustainable, needs timely decisions based on evidence. Examining the contemporary health system in Sri Lanka provides some insights to this discussion.

\section{Sri Lankan health system}

Medical pluralism, having several medical systems and different types of healers, is well documented in Sri Lanka [3-5]. Thus, patients in Sri Lanka have a variety of consultation choices: between private and government-sponsored cosmopolitan medicine, pharmacists that sell homeopathic, cosmopolitan and various forms of medicine, government sponsored and private practitioners of Ayurveda, Unani and Siddha medicines, astrologers, Buddhist monks and priest; and traditional specialist like fracture-healers, snake bite-healers, boilhealers eye disease-healers and many others [6]. Hence, Sri Lankan Health system historically goes beyond a western biomedical dimension to include many players outside the conventional system. However, recent data suggest that Sri Lankan health system is in the verge of losing its pluralistic nature and converging primarily on western medicine $[7,8]$.

Although private healthcare was an integral part of Sri Lankan health system from early nineteenth century, its stake was minimal till 1977. Change of economic policies and liberalization of trade in post 1977 era showed rapid expansion of private healthcare provision in Sri Lanka. It was further widened with the establishment of the Board of Investment and incentives for foreign direct investments in the health sector $[9,10]$. Expansion of private sector, particularly the western medical establishments, influenced the health seeking behaviour of the population. Further, expectations of medical care of the population also underwent changes instituting "bypassing" of smaller hospitals to reach larger hospitals even for miner health issues [11,12]. Underutilization of smaller hospitals and over utilization of larger secondary and tertiary hospitals due to unnecessary "bypassing" is now threatening the sustainability of state health services.

\section{Free health services as a measure of equity}

From the inception of the civil medical department in 1856, there was some degree of a free of charge health services provided by the government to the people in Sri Lanka [13]. Although it was restricted to a minority in the early days, the concept prevailed. With the establishment of "district hospitals", primarily to cater plantation workers, free of charge services at the point of delivery made more in roads towards a universal health services in Sri Lanka. Malaria epidemic in 1930's, granting of universal franchise and changing the hands of political and administrative power to locals, further strengthened the meaning of free health care by the time of independence from the British in 1948. Since the adaptation of welfare policies in governance of the country, particularly in health, education, agriculture and to some extent transport sector by subsequent 
governments made long-lasting expectations on equitable solutions for the day to day issues of the people. Within this atmosphere it is of paramount importance to explore the possibility of sustaining an equitable health system at a time of economic and political turbulence.

\section{Leadership and governance}

Responsibility of sustaining an equitable health system is beyond the ministry of health. Health ministry being the focal point in the administrative setup should be able to solicit support from the political leadership and the administrative network in the state and the private sector to achieve the goals of sustaining an equitable system. In a complex and evolving political and governing structure, compartmentalized decision making in health sector no longer delivers expected outcomes. Hence, for a sustainable and equitable health system to prevail, inter-sectoral approach with the participation of all stake holders is necessary.

One of the examples that could illustrate this paradox is the efforts and colossal amount of resources invested in improving nutritional status of the population in Sri Lanka. For over a half a century, many policy documents had been papered, dozens of programs were planned and implemented to combat malnutrition. Many studies were done to generate evidence on nutritional status of the population and the effect of interventions. However, it is clear that country has only achieved marginal successes in improving under nutrition while creating new challenges of over nutrition and obesity. The efforts made to combat this major problem were rather piecemeal, coordinated by many agencies and largely non-complimentary to each other in saving scares resources. It is unclear how stakeholders outside the health sector such as trade, agriculture, education and plantation management contributed towards a holistic approach of combating nutritional issues in the population. Such endeavors need appropriate governance structures that are able to coordinate all sectors and players related to the issue. Evidence from success stories need to be given due place in shaping governance decisions.

\section{Health information system}

Information on health at the grass root level and feedback on the process of implementing policies is mandatory for sustaining a system. Health is no exception. The decisions making on health sector should be well informed from the past experiences and current information. When examining the management information system for health in Sri Lanka, mixed results of successes and failures are seen. Although the quality of data may have issues, for a large extent preventive health services do have a functioning information system. The information system for curative health care does not yield expected results. It is a known fact that only a fraction of inpatient records are analyzed. Outpatient services data is limited for the headcount at the most. While acknowledging half of the ambulatory caretaker place in the private sector, the health system has failed to establish a continuous information flow from the private sector for decision making.

In the absence of reliable information, opinions and individual interest dominate the policy making cycles. Apart from the short supply of evidence, the extent to which the available evidence is used in policy making and implementation is also questionable. Ignorance of the policy makers towards evidence is reflected through non coherent decisions taken on vital health issues.

\section{Health financing}

At present the state health expenditure is financed through general taxation. This has continued for past 8 decades to deliver a free of charge health service at the point of delivery at state health institutions. Private health care is available for the population in a fee levying basis parallel to the state health care services for over a century. The Sri Lanka National Health Accounts highlights many facts that need urgent attention of all stakeholders in the health system [14]. As it was evident in the previous reports on Sri Lanka National Health Accounts (SLNHA), the country has not been able to sustain the spending on health on par with the overall improvement in Gross Domestic Product. Although the amount of spending has increased in rupee value, at constant price of 2002, the health spending is almost stagnant during the period concerned. In addition, spending on health by the state sector as a percentage of GDP has actually declined raising many questions. The most striking feature is the constant increase of the private share of total health expenditure in the country which remained around $51 \%$ for the period. This is further complicated by the fact that Out-of-Pocket financing for health, which is considered the most unacceptable mode of health financing leading to catastrophic consequences for households, has again increased to $46 \%$ of total health expenditure by 2009 [14].

Although there have been discussions and policy directives on increasing the allocation for preventive and public health services, the SLNHA clearly shows that percentage spending has not gone beyond $6 \%$ of total health expenditure. Although Provincial Councils control the majority of the health institutions and care services, they mainly rely on the central government grants for functioning. Except for the Western province, the general revenue of all other provinces continues to be low. It is also reflected in the per capita health expenditure in the Western Province which is twice or higher than most of the other provinces. Hence, the evidence of the financing side of the health need to be given due consideration in sustaining the health system.

\section{Human resources for health}

Human resource (HR) to operate the system is essential for smooth functioning. Each category of staff whether directly or indirectly related to the system should work harmoniously as those functions are complimentary to each other. Hence, decision making on HR needs in health sector should concentrate beyond the preparation of carder projections. Giving due considerations to epidemiological and demographic transition, evolution of new technologies, changes in health financing, human rights and labour laws, new order of global health governance, consumer activism and trade unionism is mandatory for effective HR management in health sector. Policy makers need to be well informed on all those factors for them to make rational decisions on human resource management. One of the major lapses in HR management in Sri Lanka is the lack of qualified pharmacists and other paramedical professionals. Although most countries in South Asian region embarked on graduate level training on pharmacists several decades ago, Sri Lanka continued to be satisfied only providing basic skills in managing a dispensary for the trainees. This prevented the progress of pharmaceutical sector in the country and creating serious deficiencies in medicines supply chain.

\section{Essential medical products and technologies}

Continuous supply of medicinal drugs, other consumables and equipment plays a pivotal role in healthcare delivery. It is directly 
related to the quality of care provided, treatment outcome and patient satisfaction. Provision of medicinal drugs in the state sector is one of the main components of free health services in Sri Lanka. Patients clearly identify the reason for visiting the state hospitals as provision of free consultancy and free medicines [15]. In this circumstances regular out of stock situations and unavailability of essential medicines in the hospitals threatens the sustenance of an equitable health care delivery. Rising out of pocket expenditure on side of the patients is directly attributed to the unavailability of essential medicines in the hospitals and unregulated medicines prices in the retail market. In addition, as mentioned above unavailability of medicines is also related to noncompliance, poor treatment outcomes and unnecessary burden on the health system in economic terms as well as reduction in quality of life. Hence, decisions on the provision of essential medicines at correct times in adequate quantity are a prerequisite to sustain a health system. Generating evidence for corrective action through drug utilization research and system checks is fundamental to provision of quality medicinal drugs at affordable prices.

\section{Service delivery}

Service delivery is the observable output of the health system. The return for all the resources spent on the health system is assessed by the quantity and quality of the services provided to the population in the short run and the improvement of the health status of the population as the long term gain. Hence the delivery structure of the services, quantity and quality of the services provided, patient satisfaction as well as the provider satisfaction is utmost important for improving the efficiency of a health system. Hence, information on availability and affordability of health services to all segments of the population, responsiveness of the health services to the patient needs, morbidity and mortality trends, health seeking behaviour of populations and other vital statistics need to be duly considered in decisions made on service delivery.

\section{Using Evidence in decision making}

Resources are limiting factor in any setting. Finances directed to health by the state are mostly considered as welfare expenditure than as an investment in most economies. This belief is heavily supported in economies where neoliberal political ideology is gaining control. In post WTO era where health is defined as a tradable commodity than a public good, investing in health by the state is not encouraged. Rather, allowing provision of healthcare to be decided by the market forces supply and demand is becoming the practice [16]. This effectively removes the burden as well as the responsibility of provision of healthcare from state actors.

As emphasized above the burden of advocating and maintaining health as a "public good" where, state has a historically endorsed and humanly inseparable role, rests on the health and other professionals. Generating, collating and presenting "evidence" to support such a course than allowing opinions and individual interest to govern policy cycles becomes the responsibility of professionals. Responding positively to this responsibility is a challenge in any political setup. This is more difficult in governance mechanisms where, professionals with integrity and vision find it difficult to reach decision making positions. This paves the way for narrow political agenda supported by "opportunistic" professionals to guide the decision making.
Generating usable evidence and transforming those to practical action is the way forward to sail through administrative barriers and to defeat opportunistic agendas. This is extremely relevant in the field of health, especially in low and middle income settings, where individual opinions and backdoor advocacy is playing a crucial stake in decision making. Lack of evidence as well as inadequacy of processing evidence into policy guidance is seen as chronic ailments in the health systems of many low and middle income countries. However, the decisions pertaining to healthcare are decisions of life and death, not only for individuals but for the whole communities. Hence, evidence informed policy decision in the health system is crucial for the equity and sustainability.

\section{References}

1. Pedersen D, Baruffati V (1989) Healers, deities, saints and doctors: Elements for the analysis of medical systems. Soc Sci Med 29: 487-496.

2. World Health Organization 2007 Everybody business: strengthening health systems to improve health outcomes: WHO's framework for action. Geneva: WHO.

3. De Silva MWA, Wijekoon A, Hornik R, Martines J (2001) Care seeking in Sri Lanka: one possible explanation for low childhood mortality. Soc Sci Med 53: 1363-1372.

4. Nichter M, Nordstrom C (1989) A question of medicine answering: health commodification and the social relationships of healing in Sri Lanka. Cult Med Psychiatry 13: 367-390.

5. Caldwell J, Gajanayake I, Caldwell P, Peiris I (1989) Sensitization to illness and the risk of death: an explanation for Sri Lanka's approach to good health for all. Soc Sci Med 28: 365-379.

6. Wolffers I (1988) Illness behaviour in Sri Lanka: Results of a survey in two Sinhalese communities. Soc Sci Med 27: 545-552.

7. Weerasinghe MC, Fernando DN (2011) Paradox in Treatment Seeking: An Experience From Rural Sri Lanka. Qual Health Res 21: 365-372.

8. Central Bank of Sri Lanka, 2004. Consumer Finance and Socio Economic Survey. Colombo: Central Bank.

9. Weerasinghe MC, Fernando DN (2009) Access to care in a Plural Health System: Concerns for policy reforms. Journal of Community Physicians of Sri Lanka 14: 39-45.

10. Rannan Eliya R P, Kalyanarathne A (2005) Fiscal incentives for the development of health services in Sri Lanka, Report 3, National Commission on Macroeconomics and Health Sri Lanka Colombo: Ministry of Health and Nutrition.

11. Perera SK, Weerasinghe MC (2015) Bypassing primary care in Sri Lanka: a comparative study on reasons and satisfaction. Vietnam Journal of Public Health 3.

12. Akin J, Hutchison P (1999) Health care facility choice and the phenomenon of bypassing. Health Policy Plann 14: 135-151.

13. Uragoda CG (1987) A History of Medicine in Sri Lanka. Colombo: Sri Lanka Medical Association.

14. Institute of Policy Studies 2012. Sri Lanka National Health Accounts 2005-2009. Colombo: IPS.

15. Weerasinghe MC (2008) Concerns for policy: Comprehensive economic partnership agreement in relation to health sector. Journal of Community Physicians of Sri Lanka 13: 35-39.

16. Keane C R, Weerasinghe, M C, Public Private Mix in Health Systems. In Guy Carrin, Kent Buse, Kristian Heggenhougen, Stella R Quah editors Health systems policy, finance, and organization, 1st Edition San Diego: Academic Press; 2009. pp. 314-321. 